\title{
MODOS DE AGIR DE TEXTOS DIDÁTICOS DE CIÊNCIAS: DISCUTINDO O TEMA SAÚDE E AMBIENTE
}

\author{
ACTION MODES OF EDUCATIONAL TEXTS ON SCIENCE: DISCUSSING THE HEALTH AND \\ ENVIRONMENT ISSUE
}

Francine Pinhão ${ }^{1}$

Isabel Martins $^{2}$

Resumo Neste artigo, investiga-se a temática saúde e ambiente em uma coleção didática de ciências para o Ensino Fundamental com base no referencial teórico metodológico da análise crítica do discurso. Com a finalidade de pesquisar o significado acional do texto, foram utilizados os conceitos de gênero e pré-gênero, por meio dos quais identificaram-se três principais grupos de estruturas genéricas: descritivos, explicativos e narrativos. A análise dessas estruturas indica modos de agir disciplinadores de identidades sociais, relações sociais e sistemas de conhecimento e crença.

Palavras-chave saúde; ambiente; ensino de ciências; materiais didáticos.
Abstract This article investigates the health and environment issue as presented in an educational collection on science for Elementary Education based on the theoretical framework of critical discourse analysis. The gender and pre-gender concepts were used to research the actional meaning of the text through which three main groups of generic structures were identified: descriptive, explanatory, and narrative. By analyzing these structures, one can find action modes that discipline social identities, social relations, and knowledge and belief systems.

Keywords health; environment; science education; teaching materials. 


\section{Introdução}

Investiga-se neste artigo a temática saúde e ambiente em uma coleção didática de ciências para o Ensino Fundamental intitulada Projeto Araribá. ${ }^{3}$ A escolha da temática se justifica por seu caráter transversal nos currículos da educação básica (Brasil, 1997), enquanto o foco na disciplina Ciências se relaciona ao fato de, historicamente, os conteúdos de saúde e ambiente ficarem sob a responsabilidade do professor dessa disciplina. Já a coleção didática foi selecionada pelo critério de distribuição nacional. Ela foi a mais distribuída das 11 coleções aprovadas no ano de 2008, com 1.032.696 coleções, do total de 3.436.203, circulando nas escolas públicas durante o período de 2009-2010.

A pergunta norteadora - De que maneira o discurso sobre a temática saúde e ambiente é construído nos textos de uma coleção didática de ciências? - será discutida com base no referencial teórico metodológico da análise crítica do discurso (ACD) (Chouliaraki, Fairclough, 1999; Fairclough, 2003), dialogando, mais especificamente, com o conceito de gênero de discurso.

A fim de se apresentar a conjuntura do problema de pesquisa, isto é, as relações de continuidade e ruptura entre a saúde humana e o meio ambiente e o modo pelo qual a disciplina Ciências representa estas relações, inicia-se uma breve discussão sobre as principais vertentes da ciência que dialogam com a temática e problematiza-se a relação entre estas e a educação. Na sequência, apresenta-se o referencial teórico metodológico, situa-se o livro didático como um gênero discursivo, descrevem-se os exercícios de análise textual e, por fim, discutem-se os resultados de pesquisa.

\section{Sobre a ruptura e as possibilidades de diálogo entre saúde e ambiente}

A partir do final do século XX, devido à evidência da crise ambiental, dos grandes surtos epidêmicos e do aumento de nossas incertezas sobre o futuro, as discussões sobre as questões de saúde e ambiente têm estado cada vez mais presentes em nosso cotidiano. Desde a década de 1970, por meio de diferentes formas, práticas e canais, tem sido possível compartihar informações e ampliar o debate em torno da relação que estas temáticas possuem com a ciência.

O modo como se conceitua saúde e ambiente e, por consequência, as relações que se estabelecem com questões ligadas a essas temáticas estão diretamente vinculados aos modos como se produz conhecimento na sociedade. Sem desprezar as múltiplas formas de produção do conhecimento, tratar-se-á aqui da produção de conhecimento científico por ela ser compreendida como legitimada e hegemônica no espaço escolar. 
Tomando como ponto de partida a relação entre a produção do conhecimento científico e as formas de conceituar saúde e ambiente pode-se dizer, resumidamente, que a relação de dominação do homem sobre a natureza, gerada pela consolidação da ciência, possibilitou uma ruptura entre homem e natureza. E, por consequência, questões relativas à saúde passaram a ser tratadas separadamente das questões ambientais ou, quando tratadas simultaneamente, dava-se uma orientação unicausal para o caráter da relação entre estas questões no âmbito da resolução de problemas.

Ávila-Pires, no livro Fundamentos históricos da ecologia, publicado em 1999, apresenta dois conceitos considerados pelas autoras potencialmente interessantes para se pensar historicamente como a ciência constrói a relação entre o meio ambiente e o desenvolvimento das doenças. São eles: meio interior e meio exterior. O meio interior, conceito desenvolvido por Claude Bernard em 1857, é definido como “constituído pelo sangue e líquidos orgânicos, abriga uma microfauna e uma microflora de organismos simbiontes, comensais, saprófitos, parasitas, ocasionais, ou necessários e permanentes" (Ávila-Pires, 1999, p. 185). Os estudos de Bernard, associados às ideias de Pasteur sobre a função dos microorganismos na infecção, levam ao desenvolvimento de uma medicina voltada para o controle microbiológico do meio interior. Por exemplo, era hábito comum na medicina a administração de substâncias como o fenol para a eliminação de microorganismos contaminantes. O trabalho de Pasteur, além de desencadear uma série de avanços sobre a noção de infecção, também abriu portas para o estudo do parasitismo e das relações que os indivíduos estabelecem com o meio exterior. Tal afirmação se deve ao fato de Pasteur ter observado que animais como os artrópodes oferecem condições internas ideais para o desenvolvimento de microorganismos e transporte de hospedeiro em hospedeiro de forma segura. Assim, indiretamente, o olhar para os microorganismos do meio interior desencadeou uma nova forma de se compreender o desenvolvimento de doenças. A partir de estudos estatísticos sobre relações interespecíficas e das interrelações entre os organismos e o meio exterior, novos enfoques de controle das doenças são propostos com base em aspectos quantitativos e preventivos.

Cabe ressaltar que, para além das relações ecológicas e dos elementos biológicos relacionados ao que foi chamado de meio externo, deve-se compreender que o fato de nos organizarmos em sociedade torna necessária a inclusão nesse meio de fatores econômicos, culturais e sociais. São de fundamental importância para se compreender como, ao longo dos tempos, a sociedade vem se constituindo e que tipos de impactos o desenvolvimento econômico e social pode gerar sobre a saúde planetária.

Atualmente, existem diversas correntes de pensamento que buscam elaborar modelos explicativos que ultrapassem a abordagem unicausal, a fim 
de potencializar a produção do conhecimento baseada em aspectos multicausais. Além das perspectivas que trabalham orientadas pelo modelo da causalidade existem vertentes que trabalham a relação ambiente e saúde de maneira ecossistêmica.

Freitas et al. (2007), ao discutirem uma abordagem ecossistêmica para a saúde, identificam atualmente duas vertentes principais. Uma é mais identificada com a mensuração de sinais e sintomas presentes no ecossistema que afetam a saúde humana e se baseia fundamentalmente na construção de informações científicas para a tomada de decisão. Já a segunda busca soluções para os problemas nos ecossistemas que se relacionam com o contexto específico e as consequências das transformações deste ecossistema para a comunidade local.

Esse breve panorama indica que a produção dicursiva da ciência é polissêmica e sugere que, de acordo com a percepção sobre a relação homemnatureza, podem ser desenvolvidos, no âmbito da educação científica, planejamentos didáticos que valorizem somente os aspectos ecológicos ou que dialoguem com os diversos aspectos envolvidos.

O ensino de Ciências deve dialogar com as múltiplas teorias científicas no sentido de apresentar ao estudante diversas formas de se discutir temáticas do seu cotidiano e revelar o caráter histórico, social e cultural das ciências.

\section{Saúde, ambiente e ensino de Ciências}

Discussões acerca do caráter histórico, social e cultural das ciências, bem como as implicações desse entendimento para o ensino de Ciências têm sido apropriadas pelos Parâmetros Curriculares Nacionais (PCNs), pelo Plano Nacional do Livro Didático (PNLD), por políticas de avaliação como o Programa Internacional de Avaliação dos Alunos (Pisa) e o Exame Nacional do Ensino Médio (Enem), bem como por professores da escola básica, seja na formação inicial ou continuada. Em vista disso, espera-se que o tratamento de temáticas emergentes em nossa sociedade seja pautado não somente por meio do conteúdo específico; no entanto, sabe-se que a história não é linear e que as mudanças no campo da prática não ocorrem de maneira imediata.

Historicamente, o tratamento das questões relacionadas à saúde no âmbito da educação escolar acontece através de dois caminhos: serviços de saúde escolar, vinculados às 'pastas de educação', ou 'programas de ensino da saúde', como, por exemplo, os PCNs. O primeiro caminho, em geral, se relaciona com práticas de controle higiênico do ambiente escolar e da inspeção da saúde física dos alunos. São ações desenvolvidas por profissionais de saúde e possuem vinculação com o tradicionalismo higiênico. O segundo caminho fica sob a responsabilidade dos professores, que, em geral, não 
recebem formação para atuar neste campo. Assim, “(...) esses programas são desenvolvidos, via de regra, com base no bom senso dos professores" (Collares e Moysés, 1985, p. 14).

No Brasil, a educação em saúde (ES) se tornou oficial e obrigatória depois da lei n. 5692/71, através da inserção dos Programas de Saúde (PS) nos currículos de Primeiro e Segundo graus. Mohr (2002), ao analisar o parecer n. 2.264/74, do Conselho Federal de Educação (CFE), que regulamentava a implementação dos PSs, aponta aspectos positivos e negativos. Itemizando os achados da autora, pode-se dizer que as orientações positivas, e até avançadas, do parecer são: o caráter não disciplinar da proposta; a inclusão dos PSs como responsabilidade de todas as disciplinas e atividades escolares; e a articulação da escola com os serviços públicos de saúde. Já os aspectos negativos dizem respeito: à não consideração da realidade escolar e da formação disciplinar dos professores; à ênfase nos aspectos empíricos e ao consequente menosprezo da teoria; e à valorização de uma educação comportamentalista (desenvolvimento de hábitos e atitudes) e bancária.

Se o documento, apesar de negligenciar aspectos da realidade escolar, representou em alguma medida avanços no que diz respeito ao tratamento do tema saúde na escola, o mesmo não pode ser considerado no âmbito da prática. De acordo com Mohr (2002), os PSs, na prática, se restringiram à criação de disciplinas, livros didáticos ou capítulos de livros e pouco se relacionavam com as questões sociais da comunidade escolar.

Retomando a ideia trazida por Collares e Moysés (1985), as práticas de ES se tornaram oficiais na escola brasileira através do segundo caminho e, por consequência, a orientação do tema acabava sendo resultado do bom senso dos professores de Ciências.

Até o final da década de 1990 a disciplina Programas de Saúde manteve-se em vigor. Só perdeu seu caráter de obrigatoriedade em 1996, com a promulgação da nova lei de diretrizes e bases da educação (lei n. 9394/96) (Spazziani, 2001). No entanto, com a formulação dos PCNs, em 1997, a saúde é novamente inserida de modo formal, mas não obrigatório, na educação básica. No documento em questão, o tema é tratado como transversal e passa a ser de responsabilidade de todas as disciplinas escolares. O documento também traz a perspectiva da integração deste tema com as questões ambientais e de educação sexual.

Atualmente, e cada vez mais, são motivados desenvolvimentos de ações escolares que levem em conta a relação dos temas ambientais com a qualidade de vida do homem e do planeta. Tendo em vista que estas questões são mais recentes do que aquelas relacionadas à saúde, os temas ambientais começam a fazer parte da escola, numa perspectiva mais voltada para o social, somente ao final dos anos 1980. 
À semelhança do que aconteceu com a inserção da ES na escola, a educação ambiental (EA) tem sua entrada pela via da política oficial. Dessa forma, o que ocorre é a orientação dos temas ambientais segundo aspectos ecológicos, muitas vezes restritos às questões técnicas de reciclagem e preservação. Além disso, os temas relacionados ao meio ambiente entram na escola, via de regra, por meio das disciplinas Ciências e Biologia. Guardam, portanto, forte relação com o saber de referência da ecologia e, em geral, os temas desta natureza entram como parte do conteúdo formal de ensino.

Além da criação de leis e setores administrativos pela inserção da EA na escola, essa ideia também é reforçada nos PCNs. Assim como o tema saúde, o tema meio ambiente passa a fazer parte do grupo de temas transversais orientados pelo documento. Além de ser tratada como transversal, a questão ambiental também é aproximada dos temas relacionados à saúde, e as orientações curriculares estimulam a abordagem dos temas de forma integrada.

O caráter de transversalidade, atribuído aos temas saúde e meio ambiente, traz uma nova perspectiva para o tratamento deles. Entretanto, uma breve leitura dos textos referentes a esses dois temas nos convida a pensar se, de fato, desde a sua implantação, houve mudanças substanciais. Ainda persiste o discurso sobre o desenvolvimento de hábitos e atitudes e, em muitos casos, os textos parecem desconsiderar a realidade escolar. Sobre estes textos, Mohr (2002) afirma que:

(...) os temas saúde e educação ambiental são concebidos como tendo uma meta única a saúde e a consciência ambiental. Estas são tratadas como se fossem entidades absolutas, não restando opção ao indivíduo (de bom senso e fruto de uma educação de qualidade) senão tentar atingi-las através de procedimentos-padrão (Mohr, 2002, p. 73).

Da mesma forma que demais projetos foram levados à escola, os PCNs invadiram o espaço escolar sem estar associados a programas de formação continuada comprometidos com o debate sobre a orientação do trabalho com temas transversais ou sobre como trabalhar um enfoque interdisciplinar. Tanto os professores de Ciências quanto os demais professores não recebem, em sua formação inicial, subsídios que possibilitem um trabalho com esses temas que os ajudem a ultrapassar a dimensão da transmissão de conteúdos básicos da ciência moderna, voltados apenas para aspectos morfológicos e funcionais.

Chama-se atenção para o fato de que estes conceitos básicos da ciência são, sim, fundamentais, mas um projeto educacional que vise à formação para a cidadania deve articular tais conhecimentos com aspectos da vida social, permitindo ao aluno conhecer não apenas os conceitos científicos, mas como eles medeiam a relação que estabelecemos com o mundo. 
Neste contexto de falta de investimento e de insuficiência da formação inicial e continuada da maioria dos professores, o livro didático passa a ser um dos principais agentes de formação e legitimação das ações docentes, constituindo-se como um instrumento por meio do qual as orientações curriculares se materializam e adentram o espaço escolar. Sobre a natureza do texto do livro didático, Martins (2006) adverte que

O texto do livro didático não é a simples adaptação do texto científico para efeito do ensino escolar, exclusivamente por meio de transposições didáticas de conteúdos de referência. Ele reflete as complexas relações entre ciências, cultura e sociedade no contexto da formação de cidadãos e se constitui a partir de interações situadas em práticas sociais típicas do ensino na escola (Martins, 2006, p. 125).

Com base nessas considerações, o livro didático pode ser compreendido como veículo de ideologias, valores, preconceitos e culturas (Bittencourt, 2004; Martins 2006).

A partir desse entendimento sobre a natureza do livro didático, do processo histórico de inserção dos temas saúde e ambiente na escola e da discussão epistemológica sobre a ruptura e aproximação entre os temas na produção científica, buscam-se subsídios na ACD para a discussão do atravessamento dessas diferentes questões no texto do livro didático, levando em consideração a ideia de que todo e qualquer texto é investido ideologicamente.

\section{Referencial teórico metodológico}

A análise crítica do discurso 4 se insere no quadro das teorias críticas por considerar a linguagem, para além de um sistema de signos, como o resultado de uma construção social. Nesse sentido, a linguagem é historicamente situada e marcada por aspectos ideológicos, hegemônicos e relações de poder (Fairclough, 2001).

O discurso é compreendido como uma "prática não apenas de representação do mundo, mas de significação do mundo, constituindo e construindo o mundo em significado" (Fairclough, 2001, p. 91). Assim, o discurso deixa de ser apenas o reflexo, a representação, a reafirmação do universo social para também construí-lo e potencialmente transformá-lo; logo, sua relação com a estrutura social é dialética. Esta característica do discurso faz dele produtor e/ou reprodutor de "identidades sociais; posições de sujeito, relações sociais" e, por fim, "sistemas de conhecimento e crença" (Fairclough, 2001, p. 91).

O esforço teórico-metodológico da ACD reside na articulação entre teorias linguísticas e sociais a fim de tornar possível a relação entre a análise 
micro (estrutura do texto) e a análise macro (estrutura social). Uma referência importante para o desenvolvimento desse quadro teórico é a gramática funcional de Halliday, mais especificamente, as macrofunções da linguagem: função identitária, função interpessoal e função textual. Foram apropriadas e reorganizadas por Fairclough (2003) em três principais tipos de significados da linguagem: acional, representacional e identificacional. Relacionam-se, respectivamente, com os seguintes conceitos: gênero discursivo, discurso e estilo. Dentre estes significados, privilegia-se nas análises o significado acional, que diz respeito ao modo como os textos agem e interagem socialmente. De acordo com Faircloigh (2003), é possível investigar a ação e a interação do texto, no interior de um evento social especifico, a partir dos gêneros discursivos que constituem uma determinada prática.

A definição de gênero discursivo de Fairclough se aproxima da conceituação de Bakhtin, que considera os gêneros de discurso como "tipos relativamente estáveis de enunciado" vinculados a esferas sociais (1992, p. 279). Para Bakhtin, os enunciados são fenômenos sociais concretos e únicos, caracterizados por um conjunto mais ou menos estável de elementos e constituídos historicamente nas atividades humanas. Dada sua característica histórica, são passíveis de adaptações e modificações ao longo do tempo, imprimindo uma grande diversidade de gêneros discursivos na sociedade.

O conceito de gênero, de acordo com Fairclough (2003), pode ser compreendido segundo diferentes níveis de abstração, que são determinados de acordo com o tipo de relação que é estabelecida entre o gênero e uma dada prática social específica. Assim, os gêneros são classificados - dos mais abstratos para os menos abstratos - como: pré-gêneros, gêneros desencaixados e gêneros situados (Fairclough, 2003, p. 68).

Os pré-gêneros são aqueles que podem ser usados para compor textos vinculados às mais diferentes práticas sociais, tais como: narração, argumentação, descrição, explicação e diálogo. Os gêneros desencaixados são os que transcendem uma prática social específica; assim, ficam disponíveis para demais redes de práticas. Um exemplo desse gênero é a entrevista, que é passível de uso em diferentes contextos sociais. Já os gêneros situados são aqueles marcados por uma prática social específica, como é o caso do livro didático.

De acordo com Fairclough (2003), apesar dos gêneros situados serem marcados por uma prática particular, não é possível prever uma estrutura genérica fixa para eles. Tendo em vista os diferentes níveis de abstração atribuídos ao conceito de gênero, Fairclough (2003) assume a possibilidade de um mesmo gênero situado ser constituído por variadas estruturas genéricas, ou seja, por diferentes pré-gêneros. Nesse sentido, um texto pertencente ao gênero situado livro didático pode ser estruturado por meio de diferentes pré-gêneros, como por exemplo: diálogo, explicação, narrativa. 
Assim, uma análise genérica baseada na identificação dos pré-gêneros torna-se potencialmente útil para se discutir os propósitos do texto, ou seja, seus modos de agir e interagir com uma temática específica.

Fairclough (2003) sinaliza como problemática uma análise de gênero que privilegie o propósito como algo determinado, pois um gênero particular pode ter vários propósitos; logo, dificilmente se encontram estruturas genéricas claras. Não se procura, portanto, encontrar padrões de composição genérica predeterminados, pois o propósito de um texto didático pode variar tanto quanto a diversidade de entendimentos existentes sobre quais as finalidades de se ensinar. Desta forma, entende-se que é possível haver num mesmo livro didático propósitos que variam desde a transmissão de informações até o desenvolvimento de capacidade crítica dos alunos.

\section{Apresentação das análises}

\section{O corpus}

O corpus da pesquisa foi selecionado mediante critérios da análise de conteúdo. A escolha por essa metodologia diz respeito à possibilidade de se conseguir extrair da coleção didática os textos mais significativos para a pesquisa. Esta possibilidade reside no uso dos seguintes parâmetros de seleção: exaustividade, homegeneidade e pertinência, conforme elaborados por Bardin (1977). Tais parâmetros, associados à condição dos textos necessariamente dialogarem com a temática saúde e ambiente por meio de aspectos sociais, econômicos e culturais, sanitários, ecológicos e biomédicos, levaram à seleção de seis textos do total da coleção, os quais são apresentados a seguir.

Quadro 1

Textos selecionados para compor o corpus

\begin{tabular}{|c|c|c|c|c|}
\hline \multicolumn{5}{|c|}{ Livro 5.a série } \\
\hline Série & Título & Unidade & Tópico & Seção \\
\hline 5. a série & $\begin{array}{l}\text { Como reduzir a poluição } \\
\text { do solo? }\end{array}$ & $\begin{array}{l}\text { Unidade } 3 \text { - Conhecendo } \\
\text { o solo }\end{array}$ & O solo e a saúde & $\begin{array}{l}\text { Por uma nova atitude } \\
\text { (p. 78-79) }\end{array}$ \\
\hline 5. a série & A contaminação da água & Unidade 4 - A água na Terra & O ciclo da água & Explore (p. 91) \\
\hline 6. a série & $\begin{array}{l}\text { Manguezais: exploração e } \\
\text { preservação }\end{array}$ & $\begin{array}{l}\text { Unidade } 8 \text { - Variedade de } \\
\text { ecossistemas }\end{array}$ & $\begin{array}{l}\text { O Pantanal mato-grossense } \\
\text { e os manguezais }\end{array}$ & $\begin{array}{l}\text { Por uma nova atitude } \\
\text { (p. 190-191) }\end{array}$ \\
\hline
\end{tabular}


Continuação - Quadro 1

\begin{tabular}{|c|c|c|c|c|}
\hline \multicolumn{5}{|c|}{ Livro 5. a série } \\
\hline Série & Título & Unidade & Tópico & Seção \\
\hline 6. ${ }^{\text {a série }}$ & Lagoa Azul está doente & $\begin{array}{l}\text { Unidade } 7 \text { - O reino animal: } \\
\text { os invertebrados }\end{array}$ & Parasitoses & Explore (p.167) \\
\hline 6. ${ }^{\text {a série }}$ & Animais de estimação & $\begin{array}{l}\text { Unidade } 8 \text { - O reino animal: } \\
\text { Os vertebrados }\end{array}$ & Os mamíferos & Por uma nova atitude (p. 192) \\
\hline 8. ${ }^{\text {a série }}$ & A tintura de tecidos & $\begin{array}{l}\text { Unidade } 2 \text { - As transformações } \\
\text { dos materiais }\end{array}$ & As reações químicas & Explore (p. 49) \\
\hline
\end{tabular}

Fonte: as autoras.

Uma vez definido o conjunto de textos que constitui o corpus, iniciou-se, de acordo com as bases teóricas da ACD, uma análise textual que privilegiou aspectos relativos ao gênero e que foi desenvolvida com base em aspectos tratados na análise de conjuntura que, como discutido na seção anterior, exploravam as relações conceituais, históricas e políticas entre saúde e ambiente e suas repercussões no campo educacional. No âmbito deste artigo, para a apresentação da análise genérica, optou-se por fazer uma síntese dos aspectos gerais encontrados nos textos, trazendo exemplos mais representativos de cada construção textual. Assim, os textos foram agrupados de acordo com o pré-gênero mais expressivo e chegou-se aos seguintes grupos de textos: descritivos, explicativos e narrativos. Apresenta-se a seguir uma sequência que ilustra os procedimentos analíticos e que mobiliza os resultados principais da pesquisa.

\section{A estrutura genérica}

\section{Descritivos}

Uma sequência descritiva é caracterizada por uma construção vertical, constituída de três etapas organizadas hierarquicamente, conforme apresentado a seguir. 
Quadro 2

Sequência hierárquica do pré-gênero descritivo (Adam, 1985 apud Brandão, 2003)

\begin{tabular}{ll}
\hline \multicolumn{1}{c}{ Etapa } & Descrição da etapa \\
\hline Ancoragem & Nominalização ou tema-título do que será descrito. \\
Aspectualização & As partes do tema, ou seja, quais os aspectos envolvidos no tema. \\
Relacionamento & A forma como os aspectos presentes no texto são relacionados. \\
\hline
\end{tabular}

Fonte: as autoras.

Localizou-se nesta categoria um total de três textos: texto 1 "Manguezais: exploração e preservação"; texto 2 - "Animais de estimação"; e texto 3 - "A tintura de tecidos". Optou-se por apresentar a análise do texto 1, por ser o mais característico deles, e apenas comentar os demais.

O texto 1 é constituído predominantemente pelo pré-gênero descritivo. Sua orientação é para a exposição de informações sobre a importância do ecossistema manguezal - na manutenção da biodiversidade - e o problema do trabalho infantil nos manguezais.

A ancoragem é realizada por meio de um tema-título, a saber, "manguezais: exploração e preservação".

Com relação à aspectualização, verificou-se o uso do aspecto científico com a finalidade de respaldar a importância da preservação do manguezal. Este aspecto foi caracterizado pelo uso de dados estatísticos sobre o número de espécies da região.

O manguezal tem poucas espécies de árvores - menos de $1 \%$ das registradas na mata atlântica -, mas abriga uma enorme diversidade de microalgas. (...) Pelo menos 80 espécies de animais comercialmente importantes dependem desse ecossistema (Livro 5. ${ }^{a}$ Série, p. 190).

O uso do aspecto social para a descrição do problema limita-se a relacionar, de maneira unicausal, o aumento do número de crianças e de adultos que praticam a pesca predatória ao aumento do desemprego.

(...) O problema tem se agravado ultimamente por causa da crise social e do desemprego. (...) Além disso, os caranguejos estão desaparecendo porque são pescados de forma predatória (...) (Livro 5. ${ }^{a}$ Série, p. 190).

Outra característica deste pré-gênero é a relação entre os aspectos componentes da descrição, que pode ocorrer por meio de comparação ou metáfora. 
No caso do texto "Manguezais: exploração e preservação", percebeu-se que a relação entre a importância do manguezal e o problema social é realizada no parágrafo que descreve o movimento Manguebeat e apresenta um trecho do manifesto "Caranguejos com cérebro", que possui caráter metafórico em seu título. Nesse caso, o caranguejo representa os homens, mulheres e crianças que vivem naquele ecossistema, e o reconhecimento do cérebro auxilia no entendimento de que aqueles que vivem do e no mangue também pensam. O apelo presente no título original do manifesto, originado de um movimento cultural que visa a discutir a importância do manguezal para as famílias que vivem em seu entorno, não é explorado pelo texto didático, e a discussão se restringe à questão das consequências ambientais do aterramento, como se pode verificar no trecho abaixo extraído do texto didático.

f) Leia um trecho do manifesto "Caranguejos com cérebro" e responda.

A planície costeira onde a cidade do Recife foi fundada é cortada por seis rios. Após a expulsão dos holandeses, no século XVII, passou a crescer desordenadamente às custas do aterramento indiscriminado e da destruição de seus manguezais.

Procure uma explicação para o significado da expressão 'aterramento indiscriminado'. (...) (Livro 5. Série, p. 191).

Considerou-se que a aspectualização do tema-título, bem como a relação entre os elementos que compõem o assunto limitam o entendimento da questão. Apesar de o tema saúde e ambiente não ser apresentado única e exclusivamente por meio de causas biológicas, como a existência de mosquitos e o risco de alagamento, o aspecto social, econômico e cultural é discutido de maneira limitada, atribuindo de maneira direta e unicausal a presença de crianças no manguezal ao aumento do desemprego e a pobreza. Há ausências como, por exemplo, o aspecto cultural do trabalho no manguezal e a do poder público para orientar o trabalho dessas famílias.

Nos demais textos classificados como descritivos localizou-se, por exemplo, no texto 2, "Animais de estimação", a mobilização dos aspectos políticos, afetivos e morais para o tratamento do tema-título que é "o abandono dos animais de estimação e a incidência dos casos de raiva" (Livro 6. série, p. 192). Percebeu-se, porém, que a relação entre esses aspectos não foi realizada de maneira que permitisse o entendimento da questão de forma mais completa, considerando, por exemplo, dimensões de saúde pública e de responsabilidade de instituições de proteção animal.

No texto 3, "Animais de estimação", o pré-gênero descrição é caracterizado pela apresentação de um processo e suas consequências. Na aspectualização, os autores tratam dos aspectos econômicos, ambientais e de saúde envolvidos com o tema proposto. No entanto, a apresentação dos diferentes 
aspectos é realizada sem relacionar de maneira direta tal evento com as estruturas de poder que as determinam. Tal questão pode ser ilustrada, por exemplo, pela ausência de discussões sobre a função do poder público na resolução de problemas e pela centralidade do papel dos indivíduos e de pequenos grupos.

\section{Explicativos}

As sequências descritivas e explicativas podem ser confundidas devido ao fato de ambas promoverem questionamentos do tipo como?. O que diferencia uma da outra é o fato de a primeira descrever sequências até atingir o objetivo, enquanto a explicativa constrói uma ideia. Segundo Adam (1985) apud Brandão (2003), a sequência explicativa se constitui de três fases, onde ocorrem os seguintes movimentos: levantar um questionamento, responder o questionamento, sumarizar a resposta avaliando o problema.

O texto 4, "Como reduzir a poluição do solo?", oscila entre a descrição, explicação e argumentação. A centralidade do texto está na compreensão do processo de poluição, por liberação de chorume no solo e lençol freático, bem como suas consequências e a apresentação de técnicas para a descontaminação. Os trechos descritivos se ocupam de caracterizar o solo e as técnicas de despoluição. Aqueles argumentativos apresentam uma premissa científica sobre a constituição do solo, que justifica a afirmação de que, através dos poros do solo, o chorume alcança o lençol freático, o que permite concluir que a contaminação também depende da porosidade que o solo apresenta.

A maior parte do texto é explicativa. Esta é desencadeada por uma pergunta sobre quais são as consequências do ser humano introduzir novos elementos no solo, e que é respondida por meio da apresentação de um problema, a saber, o comprometimento da fertilidade dos solos e a possibilidade de contaminação das plantas que ali cresçam. Por fim, o problema é avaliado como potencialmente prejudicial à saúde humana. O trecho abaixo exemplifica a sequência acima relatada:

Imagine o que acontece quando o ser humano decide mudar a receita de se fazer solos (...) ingredientes novos começam a ser adicionados, como resíduos industriais, fertilizantes (...) Mesmo que as sementes consigam germinar, há sempre riscos das plantas nascerem doentes e de transmitirem doenças para aqueles que se alimentam delas. (...) debaixo do solo existem verdadeiros lagos e rios, (...) se a água estiver contaminada, há sérios riscos para a saúde humana (Livro 5. Série, p. 78).

Nota-se a existência de uma discussão unicausal que estabelece ligação direta entre o consumo de água e alimentos contaminados e os riscos à 
saúde humana que desconsidera o fato de que o nosso país não possui uma gestão adequada de resíduos e que não problematiza as implicações da existência de um lixão, as quais vão desde a proliferação de vetores até a existência de famílias que veem naquele local a única fonte de alimentação e renda.

\section{Narrativos}

De acordo com Adam (1985) apud Brandão (2003), uma sequência do tipo narrativa inicia-se por meio de uma orientação que define o espaço, o tempo e as características das personagens. Na continuação, acontece uma complicação que tem por finalidade modificar uma dada situação original. Esta transformação da situação inicial corre por meio de uma ação transformadora. Nesse sentido, o processo narrativo se dá por meio de uma lógica singular, onde o que vem depois é resultado de uma causa anterior. A narrativa, então, chega a um resultado onde é estabelecido um novo estado, diferente do estado inicial da estória, e o seu final ocorre no momento em que é elaborada uma avaliação (moral), explícita ou a derivar, com base nas consequências da estória.

Localizou-se nesta categoria um total de dois textos: texto 5 - "A contaminação da água" e texto 6 - "Lagoa Azul está doente". Ambos apresentam o assunto predominantemente por meio do gênero narrativo.

O texto 5 é iniciado por um breve parágrafo descritivo que apresenta os diferentes aspectos relacionados com a formação do esgoto e a consequência de seu despejo em ambientes aquáticos. Na sequência, o texto é constituído pelo pré-gênero narrativo. A orientação define a existência de duas fábricas próximas a um rio que passa por cinco cidades diferentes. A partir desta apresentação inicial é colocada a complicação, que é a presença de peixes mortos e pessoas intoxicadas em cidades específicas. Com base no problema é proposta uma ação, que foi o envio de fiscais até as fábricas para uma análise química.

Ao longo do texto são apresentados para o leitor o resultado da análise e as demais sequências da narrativa ficam por conta do aluno, cabendo a ele avaliar a situação por meio do conhecimento científico e chegar a um novo estado ao propor formas de solucionar o problema.

Percebeu-se que o texto "A contaminação da água" atribui uma centralidade ao aspecto científico quando o problema estava sendo investigado. No entanto, a existência de questões mais abertas ao final do texto, como "Forme um grupo. Discutam e listem duas soluções possíveis para resolver o problema de poluição da água", indica a possibilidade do desenvolvimento de discussões que privilegiem ações que não se limitem à despoluição das águas. Destacou-se, no entanto, que para que isto ocorra a figura de um 
professor que promova esse tipo de debate é fundamental, pois o texto, por si só, não alcança as diferentes possibilidades de problematização exigidas pela questão.

O texto 6, "Lagoa Azul está doente", é constituído pelo pré-gênero narração e caracterizado pela apresentação de uma situação fictícia. Nela são citados os sujeitos envolvidos em um problema, a saber, os vereadores de uma pequena cidade. A complicação narrada é a existência de doenças como: doença de Chagas, esquistossomose e ascaridíase. Diante do problema são apresentadas ações que se relacionam com as diferentes dimensões do problema, desde a construção de redes de saneamento até a realização de campanhas de esclarecimento à população.

Seguindo o mesmo padrão do texto anterior, a avaliação moral e a análise ficam sob responsabilidade do leitor. Aqui ressalta-se novamente a importância do trabalho do professor para a concretização de dinâmicas que visem uma abordagem multidimensional do problema.

\section{Discussão dos resultados}

Conforme sinalizado por Fairclough (2003), a estrutura de um gênero situado não é estática. Além disso, as construções textuais estão relacionadas a práticas sociais; não nos surpreende, no contexto da diversidade de discursos, práticas e atividades que interpelam e permeiam o espaço escolar, encontrar-se uma variedade de construções textuais. Estas diferentes formas de usar os subgêneros para compor um texto se relacionam com as diferentes proposições dos autores.

Identificaram-se nas análises três principais grupos de estruturas genéricas: descritivos, explicativos e narrativos. As estruturas descritivas variam em termos de aspectualização, isto é, alguns textos tratam o assunto por meio de múltiplos aspectos enquanto outros focalizam a discussão em apenas um aspecto. Já na etapa de relacionamento, percebeu-se que em geral os aspectos mencionados nos texto aparecem de forma desconectada e, consequentemente, pouco relacionados entre si. Na sequência explicativa, percebeu-se uma construção na qual o questionamento inicial é respondido e avaliado de forma limitada, pois desconsidera demais dimensões do problema. Nos textos narrativos, verificou-se que as etapas finais, avaliação e moral são deixadas a cargo do leitor, pois foram incluídas em forma de perguntas. Ressalta-se que, tanto aqui quanto em todos os textos investigados, o professor deve desempenhar o papel de mediador das leituras para potencializar as discussões mediante diferentes olhares para um mesmo tema.

Apesar de os textos analisados serem diferentes em termos de estrutura, de proposição de ideias e de conteúdos, não se pode desconsiderar o fato de 
que em cada um deles identificaram-se também construções textuais relacionadas às finalidades de justificativa e convencimento, que são compreensíveis se for lembrado que um texto didático tem por finalidade a apreensão de conceitos e valores. Além disso, na situação empírica investigada, onde os textos do corpus situavam-se em subseções do livro voltadas especificamente ao desenvolvimento de competências e envolvidas na adoção de atitudes saudáveis e ecologicamente corretas, pode-se supor que os textos também se aproximem do propósito de argumentação.

Ao se analisar o modo pelo qual os textos agem discursivamente, através da estrutura genérica, é possível encontrar modos disciplinadores ou transformadores. De acordo com Fairclough,

a prática discursiva é constitutiva tanto de maneira convencional como criativa: contribui para reproduzir a sociedade (identidades sociais, relações sociais, sistemas de conhecimento e crença) como é, mas também contribui para transformá-la (Fairclough, 2001, p. 92).

Com base na análise das estruturas genéricas, os textos que compõem o corpus dessa pesquisa são disciplinadores, como pode ser visto no exemplo das narrativas construídas por meio de avaliações e ações pautadas apenas no conhecimento científico (texto 5 e texto 6) e nos exemplos em que, apesar da tentativa de se basear em outros aspectos, não ultrapassava o caráter comportamentalista (texto 6). As descrições baseadas em aspectos pouco relacionados com as causas sociais, históricas e econômicas (texto 1), bem como a menção a apenas um aspecto para compor a descrição de um dado tema restringem a discussão. Nesse sentido, conclui-se que existe a necessidade de uma exploração mais ampla do tema, como também a co-relação entre os aspectos envolvidos para que se possa compor um texto capaz de ultrapassar os limites da conjuntura atual, com a finalidade de estabelecer padrões transformadores em vez de disciplinadores.

\section{Conclusão}

A discussão de fundo presente nas análises se relaciona com a natureza do conhecimento científico e o modo pelo qual as produções discursivas hegemônicas no campo científico são valorizadas na educação. As produções discursivas do campo da saúde e ambiente historicamente presentes na escola estão, em geral, vinculadas a uma concepção comportamentalista da educação e afastadas de abordagens que consideram o outro do processo educativo como sujeito de ação. 
Considerando a prevalência de abordagem unicausal e a estrutura textual de caráter disciplinador, conclui-se que, apesar dos documentos oficiais e materiais didáticos enunciarem a importância dos temas emergentes na educação, como elementos de contextualização e formação para a cidadania, e da superfície material do texto conter palavras e expressões identificadas com abordagens multicausais, o uso de descritores variados não elimina o caráter disciplinador do texto e, por consequência, uma concepção comportamentalista de educação.

Sobre o uso de temas emergentes na educação, Lopes (2002) afirma que a inclusão de temas transversais com apelo social nas políticas curriculares não garante que a formação para o desenvolvimento da cidadania seja desenvolvida. Nessa mesma linha argumentativa, afirma-se que a inclusão da temática saúde e ambiente nos materiais didáticos por si não levam a uma produção discursiva transformadora.

\section{Agradecimentos}

A pesquisa tratada neste artigo foi realizada com o apoio da Coordenação de Aperfeiçoamento de Pessoal de Nível Superior (Capes/DS) e do Conselho Nacional de Desenvolvimento Científico e Tecnológico (CNPq)/Edital Ciências Humanas, 2006, órgãos aos quais fazemos o nosso agradecimento.

\section{Notas}

1 Professora assistente do Instituto de Educação de Angra dos Reis (IEAR), da Universidade Federal Fluminense (UFF), Angra dos Reis, Rio de Janeiro, Brasil. Doutoranda do curso de Pós-Graduação em Educação em Ciências e Saúde pelo Núcleo de Tecnologia Educacional para a Saúde (UFRJ-Nutes). <pinhaofl@hotmail.com>

Correspondência: Pólo Universitário Professor Jair Travassos, Avenida dos Trabalhadores, s/n., CEP 23900-000, Jacuecanga, Angra dos Reis, Rio de Janeiro, Brasil.

2 Professora associada da Universidade Federal do Rio de Janeiro (UFRJ), Rio de Janeiro, Brasil. Doutora em Educação pelo Institute of Education da Universidade de Londres. <isabelmartins@ufrj.br> 
3 Todos os dados estatísticos referentes às coleções foram concedidos, via correspondência eletrônica, pela Coordenação Geral dos Programas do Livro/Fundo Nacional de Desenvolvimento da Educação (CGPLI/FNDE).

4 Este termo foi cunhado por Fairclough, no ano de 1985, em artigo publicado no periódico Journal of Pragmatics (Resende e Ramalho, 2006).

5 O manisfesto "Manguebeat", de autoria de Fred Zero Quatro, líder do movimento, pode ser acessado em <www.fafich.ufmg.br/manifestoa/pdf/caranguejos > .

\section{Referências}

AVILA-PIRES, Fernando D. Fundamentos históricos da ecologia. 1. ed. Ribeirão Preto: Holos, 1999.

BAKHTIN, Michael. Estética da criação verbal. São Paulo: Martins Fontes, 1992.

BARDIN, Laurence. Análise de conteúdo. Lisboa: Edições 70, 1977.

BITTENCOURT, Circe Maria Fernandes Apresentação da seção 'Em Foco': História, produção e memória do livro didático. Educação e Pesquisa, São Paulo, v. 30, n. 3, p. 471-473, set./dez. 2004.

BRANDÃO, Helena Nagamine. Texto, gêneros do discurso e ensino. In:

(Coord.). Gêneros do discurso na escola: mito, conto, cordel, discurso polítco, divulgação científica. São Paulo: Cortez, 2003. p. 17-46.

BRASIL. Ministério da Educação. Parâmetros curriculares nacionais. Brasília, DF: MEC, 1997. Disponível em: <http://portal.mec. gov.br>. Acesso em: jul. 2008.

CHOULIARAKI, Lilie; FAIRCLOUGH, Norman Discourse in Late Modernity: Rethinking Critical Discourse Analysis. Edinburgh: Edinburgh University Press, 1999.
COLLARES, Cecília Azevedo Lima; MOYSÉS, Maria Aparecida Afonso. Educação ou saúde? Educação $\mathrm{X}$ saúde? Educação e saúde! Caderno Cedes - Fracasso escolar: uma questão médica?, São Paulo, n. 15, p. 7-16, 1985.

FAIRCLOUGH, Norman Discurso e mudança social. Brasília, DF: Universidade de Brasília, 2001.

- Analysing Discourse: Textual Analysis for Social Research. New York: Routledge, 2003.

FREITAS, Carlos Machado; OLIVEIRA, Simone Gomes de; SCHÜTZ, Gabriel Eduardo; FREITAS, Marcelo Bessa; CAMPONOVO, Mariana Panchita Gómez. Ecosystem approaches and health in Latin America. Cadernos de Saúde Pública, Rio de Janeiro, v. 23, n. 2, p. 283-296, 2007.

LOPES, Alice Casimiro. A integração curricular em textos de ciências para o ensino médio. (Projeto Integrado de Pesquisa), 2002. Disponível em: <www.curriculouerj.pro.br/docs/a_integracao_curricular_ em_textos_de_ciencias_para_o_ensino_ medio.pdf $>$. Acesso em: jul. 2008.

MARTINS, Isabel Analisando livros didáticos na perspectiva dos estudos de discurso: 
compartilhando reflexões e sugerindo uma agenda para a pesquisa. Revista Pro-Posições, Campinas, v. 17, n. 1, p. 49, 2006.

MORH, Adriana. A natureza da educação em saúde no ensino fundamental e os professores de ciências. 2002. Tese (Doutorado em Educação) - Universidade Federal de Santa Catarina, UFSC.

RESENDE, Viviane de Melo; RAMALHO, Viviane. Análise de discurso crítica. São Paulo: Contexto, 2006. 158 p.
SPAZZIANI, Maria de Lourdes. A saúde na escola: da medicalizacão à perspectiva da psicologia histórico-cultural. Educação Temática Digital, Campinas, v. 3, n. 1, p. 41-62, dez. 2001.

Recebido em 29/10/2011

Aprovado em 09/12/2012 